\title{
Medical Student Contributions In The Workplace: Can We Put a Value on Priceless?
}

\author{
J. M. Ehrenfeld ${ }^{1}$ - W. Anderson Spickard III ${ }^{1}$ - W. B. Cutrer ${ }^{1}$
}

Received: 3 April 2016/Accepted: 7 April 2016/Published online: 14 April 2016

(C) Springer Science+Business Media New York 2016

As healthcare reform evolves, economic pressure intensifies, and education budgets come under increased scrutiny, there is growing interest in understanding the specific contributions of medical students to patient care and the healthcare settings in which they train and participate. Contributions may include patient-centered (i.e. health coaching) [1] and team-centered assistance (i.e. prevention of errors) [2]. However, there are many challenges to measuring this value [3].

The first challenge is we have little shared understanding of how we define either value or contributions. For example, many medical school faculty can point to specific instances in which their student contributions have been invaluable, but very few have an overarching framework for identifying overall value. Second, in a complex team setting, understanding the unique contributions of a single team member is difficult and in some cases impossible. As healthcare teams increasingly rely on a multitude of interprofessional team members (i.e. nursing, social work, pharmacy, physical therapy, etc.) individual roles and contributions become further blended. Finally, as many more medical schools are blurring the lines between the traditional Flexnerian $2+2$ year model (i.e. 2 years of basic science followed by 2 years of clinical rotations) and incorporate earlier clinical rotations (i.e. after 1 year rather than 2) faculty struggle to understand the developmental trajectory and therefore roles and contributions of medical students in the workplace.

In order to move our collective understanding of this problem forward, we propose that a series of research projects be

This article is part of the Topical Collection on Education \& Training

J. M. Ehrenfeld

jesse.ehrenfeld@vanderbilt.edu

1 Vanderbilt University School of Medicine, Nashville, TN, USA undertaken. It would be very helpful to define nomenclature around medical student contributions. This would then enable stakeholders to quantify contributions across settings and students. A better understanding of the typical progression of a medical student could additionally solidify faculty expectations of students and clarify the appropriate assessment of their work. Establishment of competency goals for medical students in the workplace will help to ensure that every graduate is prepared for practice. Recording of medical students' observable abilities, such as the demonstration of entrustable professional activities [4], may allow a transparent means to monitor their development as physician learners.

Medical students and other workplace learners provide immense value to patients, healthcare teams, and the systems in which they work. Although we may never be able to fully quantify this value, having a better understanding of its scope and magnitude is an important and achievable goal.

\section{Compliance with Ethical Standards}

Funding Financial support was received from the American Medical Association (AMA) aspart of the Accelerating Change in Medical Education Initiative. The content reflects the views of the authors and does not necessarily represent the views of AMA or other participants in this Initiative.

\section{References}

1. Smith, S. E., Tallentire, V. R., Cameron, H. S., and Wood, S. M., The effects of contributing to patient care on medical students' workplace learning. Med. Educ. 47(12):1184-1196, 2013.

2. Seiden, S. C., Galvan, C., and Lamm, R., Role of medical students in preventing patient harm and enhancing patient safety. Qual. Saf. Health Care. 15(4):272-276, 2006. 
3. Lin, S. Y., Schillinger, E., and Irby, D. M., Value-added medical education: engaging future doctors to transform health care delivery today. J. Gen. Intern. Med. 30(2):150-151, 2015 .
4. Hauer, K. E., Boscardin, C., Fulton, T. B., Lucey, C., Oza, S., and Teherani, A., Using a curricular vision to define entrustable professional activities for medical student assessment. J. Gen. Intern. Med. 30(9):1344-1388, 2015. 